\title{
Intraseasonal variability of sea surface height in the Bay of Bengal
}

\author{
Xuhua Cheng, ${ }^{1,2}$ Shang-Ping Xie, ${ }^{2,3}$ Julian P. McCreary, ${ }^{2}$ Yiquan Qi, ${ }^{1}$ and Yan Du ${ }^{1}$ \\ Received 25 June 2012; revised 24 December 2012; accepted 28 December 2012; published 14 February 2013.
}

[1] Intraseasonal variability (ISV) of sea surface height (SSH) over the Bay of Bengal (BoB) is studied using altimetry data and an eddy-resolving ocean model. In both the model hindcast and satellite observations, large SSH ISV is found along the eastern and northern coasts of the $\mathrm{BoB}$, in the western $\mathrm{BoB}$, and in a zonal band across the Bay centered near $5^{\circ} \mathrm{N}$. The ISV displays a clear seasonality. In the western BoB, it reaches its annual maximum in spring, whereas it does so in summer and autumn southeast of Sri Lanka. Driven by equatorial intraseasonal winds, equatorial Kelvin waves propagate eastward, reach the western coast of Sumatra, and reflect there to propagate around the perimeter of the $\mathrm{BoB}$ as coastally trapped waves. Two distinct bands of high eddy activity are detected in the western and central BoB, respectively. In both bands, isolated eddies propagate southwestward. Eddy formation in the eddy train in the central Bay is linked to the coastal wave as it bends around the corner of the Irrawaddy Delta off Myanmar. Eddy activity contributes to the high ISV in the central Bay to some extent. An energetics analysis indicates that high total eddy energy in the western BoB is due to barotropic/ baroclinic instability of the mean current.

Citation: Cheng, X., S.-P. Xie, J. P. McCreary, Y. Qi, and Y. Du (2013), Intraseasonal variability of sea surface height in the Bay of Bengal, J. Geophys. Res. Oceans, 118, 816-830, doi:10.1002/jgrc.20075.

\section{Introduction}

[2] The Bay of Bengal (BoB) is situated in the northeastern Indian Ocean (Figure 1). Ocean circulation in the BoB is forced locally by seasonally reversing monsoon winds and remotely by the winds in the equatorial Indian Ocean (IO) [McCreary et al., 1993; Schott and McCreary, 2001]. The basin-wide circulation in the bay is cyclonic during the early northeast monsoon in November and anticyclonic during the early southwest monsoon [Yu et al., 1991; Shetye et al., 1993; Eigenheer and Quadfasel, 2000; Somayajulu et al., 2003]. The East Indian Coastal Current (EICC) turns northward in February and reaches its maximum strength in April-May [Shetye et al., 1993]. South of Sri Lanka, the Southwest Monsoon Current (SMC) flows eastward and brings the salty Arabian Sea water into the BoB [Jensen, 2001]. During the winter monsoon, the Northeast Monsoon Current flows westward across the basin, carrying the fresh

\footnotetext{
${ }^{1}$ State Key Laboratory of Tropical Oceanography, South China Sea Institute of Oceanology, Chinese Academy of Sciences, Guangzhou, China.

${ }^{2}$ International Pacific Research Center, University of Hawaii at Manoa, Honolulu, Hawaii, USA.

${ }^{3}$ Physical Oceanography Laboratory, Ocean University of China, Qingdao, China.

Corresponding author: X. Cheng, State Key Laboratory of Tropical Oceanography, South China Sea Institute of Oceanology, Chinese Academy of Sciences, 164 W. Xingang Rd., Guangzhou 510301, China. (xuhuacheng@scsio.ac.cn)

(C) 2013 American Geophysical Union. All Rights Reserved.

2169-9275/13/10.1002/jgrc.20075
}

BoB water into the Arabian Sea [Jensen, 2001; Schott and McCreary, 2001].

[3] Sea level is a good indicator of changes in the upper circulation as well as water properties. Sea level varies over the $\mathrm{BoB}$ on a wide range of timescales [Han and Webster, 2002]. Seasonal variability of sea level along coastal regions is induced by two pairs of alternate upwelling- and downwelling-favorable Kelvin waves driven by equatorial winds [Rao et al., 2010]. El Niño-Southern Oscillation and the Indian Ocean Dipole affect the inter-annual variability of sea level over the BoB through equatorial and coastal wave dynamics [Clarke and Liu, 1994; Han and Webster, 2002; Rao et al., 2002; Perigaud et al., 2003; Rao et al., 2010; Sreenivas et al., 2012].

[4] Strong intraseasonal variability (ISV) is observed in the IO [e.g., Moore and McCreary, 1990; Qiu et al., 1999; Reppin et al., 1999; Sengupta et al., 2004; Han, 2005; Iskandar et al., 2005, 2006; Goswami, 2005; Miyama et al., 2006; Fu, 2007; Girishkumar et al., 2011]. There are several prominent types of oceanic ISV in the IO-Madden-Julian Oscillations (MJOs, 30-60 days), biweekly variability (14 days), and basin resonance (90 days) [e.g., Reppin et al., 1999; Han et al., 2001; Miyama et al., 2006; Horii et al., 2011]. Sea-level spectra in the equatorial IO show a dominant spectral peak at 90 days and secondary peaks at 30-60 days [Han et al., 2001; Han, 2005]. Han et al. [2011] argued that a basin "resonance" of equatorial waves causes the remarkable 90 day oceanic response. The observed 40-60 day variability in zonal surface current and sea level is forced primarily by winds associated with the MJOs. Equatorial Kelvin waves forced by MJO winds propagate eastward, reach the 


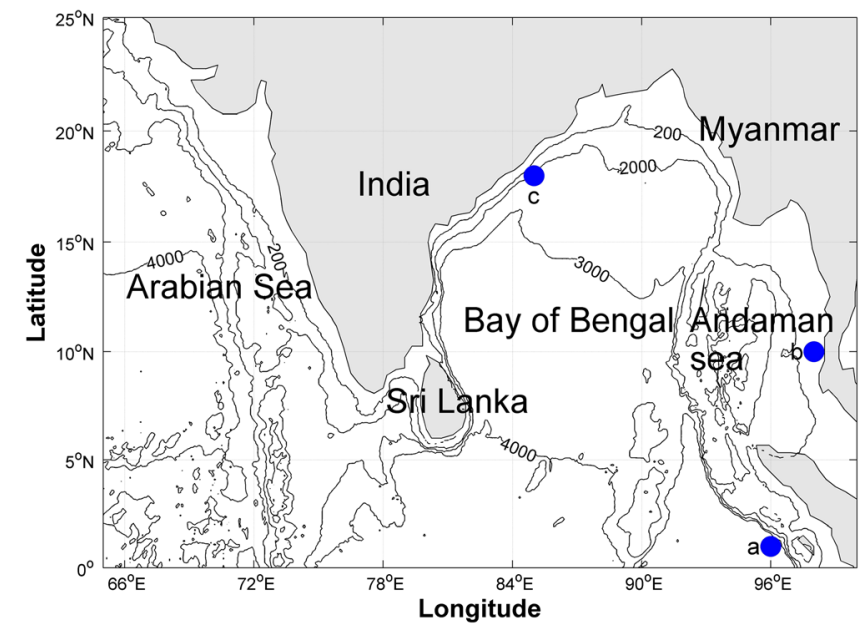

Figure 1. Bathymetry of the Bay of Bengal, with the 200, 2000, 3000, and $4000 \mathrm{~m}$ contours plotted. Sea surface height at positions $\mathrm{a}, \mathrm{b}$, and $\mathrm{c}$ are chosen for spectral analysis.

western coast of Sumatra, and propagate northward (and southward) along the coast, which impacts on the sea-level variability along the coast of the northeastern Indian Ocean [Oliver and Thompson, 2010; Vialard et al., 2009; Webber et al., 2010, 2012]. Yet, the intraseasonal Kelvin waves and their impacts on sea-level variability in the BoB have more features to be revealed, especially when eddy-resolving numerical simulations are available; high-frequency atmospheric variations, such as MJOs, are thought to be important to the region.

[5] Eddies are an important source of sea surface height (SSH) ISV along their preferred pathways. Previous studies revealed a rich mesoscale variability in the western BoB [e. g., Babu et al., 2003; Kumar et al., 2004, 2007; Kurien et al., 2010]. Using hydrographic and satellite data, Kumar et al. [2007] identified nine cold-core eddies in the central and western $\mathrm{BoB}$ during the fall inter-monsoon season of 2002 and spring inter-monsoon season of 2003. Except for these case studies, eddy activity in the BoB and its relationship to the SSH ISV have not been systematically studied. Kurien et al. [2010] analyzed mesoscale eddies and current meanders in the vicinity of the EICC during the spring inter-monsoon period, indicative of remarkable instability of the EICC. An energetics analysis has been used to evaluate contributions from instabilities of the mean flow to SSH variability, such as along the South Equatorial Current and in the South China Sea [e.g., Yu and Potemra, 2006; Zhuang et al., 2010]. Such an analysis has less been made in the BoB.

[6] The present study systematically investigates SSH ISV over the BoB and explores its dynamics, using satellite observations and results from an eddy-resolving model. The synergy of satellite observations and model simulations reveals strong ISV along the eastern and northern coasts of the BoB and in the western BoB. The present study extends previous studies by examining a broad intraseasonal band containing not only MJO-induced variability. We compare model simulations forced with the climatological and highfrequency wind products, the latter in good agreement with observations. The innovative comparison reveals that the high $\mathrm{SSH}$ variability in the western $\mathrm{BoB}$ is due to internal instabilities of the mean currents, a result corroborated by an energetics analysis. Consistent with previous studies, ISV along the eastern and northern coasts of the BoB is associated with coastally trapped waves that originate from the equator. We show that the coastal waves are significantly modulated by the westward radiation and critical latitude of the Rossby wave. As a new finding from this study, the offshore eddy shedding events and the subsequent southwest propagation are identified when the coastal wave turns around a cape in the northeast BoB.

[7] The rest of the paper is organized as follows: section 2 describes observational data and model output, section 3 examines major features of the ISV in the BoB, section 4 explores the physical mechanisms, and section 5 presents the conclusions and discussion.

\section{Data and Method}

[8] The sea-level anomaly (SLA) data used in this study are based on a merged product from multiple satellite missions (T/P and ERS-1/2, followed by Jason-1 and Envisat), distributed by Archiving, Validation, and Interpretation of Satellite Oceanographic data (AVISO, http://www.aviso. oceanobs.com/). In order to correct the aliasing of tides and barotropic variability, the altimeter data have been updated with a tidal model GOT2000 and a barotropic hydrodynamic model MOG2D-G [Volkov et al., 2007; Dibarboure et al., 2008]. The product is available on a $1 / 3^{\circ}$ Mercator grid at a weekly interval and then interpolated to daily values using cubic splines in this study. The SSH used in this study is the sum of SLA and mean dynamic topography, the latter based on GRACE data, altimetry measurements, and in situ observations (hydrologic and drifter data) [Rio et al., 2011]. We use wind stress from the QuikSCAT microwave scatterometer, available from Remote Sensing Systems (http://www.ssmi.com/) on a $1 / 4^{\circ}$ grid, with a weekly interval.

[9] We use results from three solutions (CLIM, NCEP, and QSCAT runs defined below) to an eddy-resolving OGCM for the Earth Simulator (OFES) [Masumoto et al., 2004; Sasaki et al., 2004]. The OFES model is based on the Modular Ocean Model (MOM3), with a near-global domain extending from $75^{\circ} \mathrm{S}$ to $75^{\circ} \mathrm{N}$ but excluding the Arctic Ocean. Its horizontal resolution is $0.1^{\circ}$, and it has 54 vertical levels. The model was initialized at rest with annual mean temperature and salinity from the World Ocean Atlas 1998 [Boyer and Levitus, 1997] and spun up for 50 years with monthly climatological forcing from the National Centers for Environmental Prediction/National Center for Atmospheric Research (NCEP/NCAR) reanalysis [Kalnay et al., 1996]. The precipitation rate from the NCEP/ NCAR reanalysis data is utilized to obtain the fresh water flux. In addition to the fresh water flux, OFES adopts additional restoring to the monthly mean sea surface salinity of the WOA98, with the restoring timescale of 6 days to include the contribution from the river runoff. We utilized the daily output from 1990 to 1997 of this climatological solution (CLIM run).

[10] After the spin-up integration, a hindcast simulation from 1950 to 2009 was conducted, using daily atmospheric forcing from NCEP/NCAR reanalysis (NCEP run) [Masumoto et al., 2004]. Another hindcast run starts from the NCEP run on 
20 July 1999 but is forced by the daily mean surface wind from QuikSCAT measurements (QSCAT run) [Sasaki and Nonaka, 2006; Masumoto, 2010]. The QSCAT run output during 2000-2009 is saved every 3 days for analysis.

[11] Power spectra for observed SSH along the coast of the Bay show that the dominant spectral peak in the 30-120 day band occurs at about 90 days with secondary peaks at 30-60 days (Figure 2). In this study, a Butterworth band-pass filter is used to extract intraseasonal (30-120 days) signals [Emery and Thomson, 2001]. The filter may suppress synoptic disturbances and 10-25 days of monsoon ISV, which are much weaker in SSH than those in the 30-120 day band.

\section{Features of Intraseasonal SSH Variability}

[12] Figure 3 compares the observed and simulated annual mean SSH and its intraseasonal standard deviation. The annual mean dynamic topography exhibits an anticyclonic
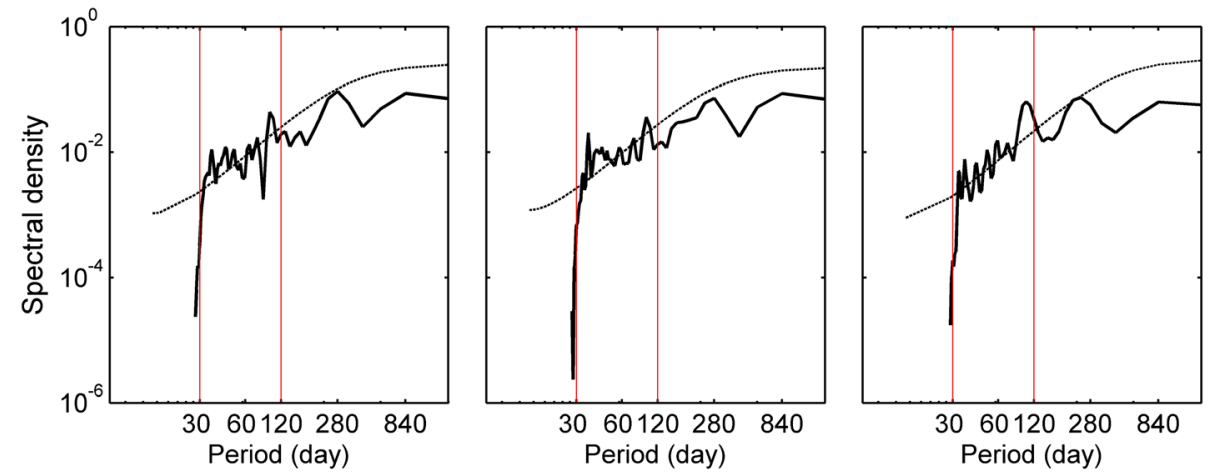

Figure 2. Power spectra for observed sea surface height (with climatology monthly mean removed). The positions selected for spectral analysis are shown by the blue dots in Figure 1 . The 95\% confidence levels are shown by dashed lines, and the red lines indicate the cutoff periods (30 and 120 days) for ISV signals.

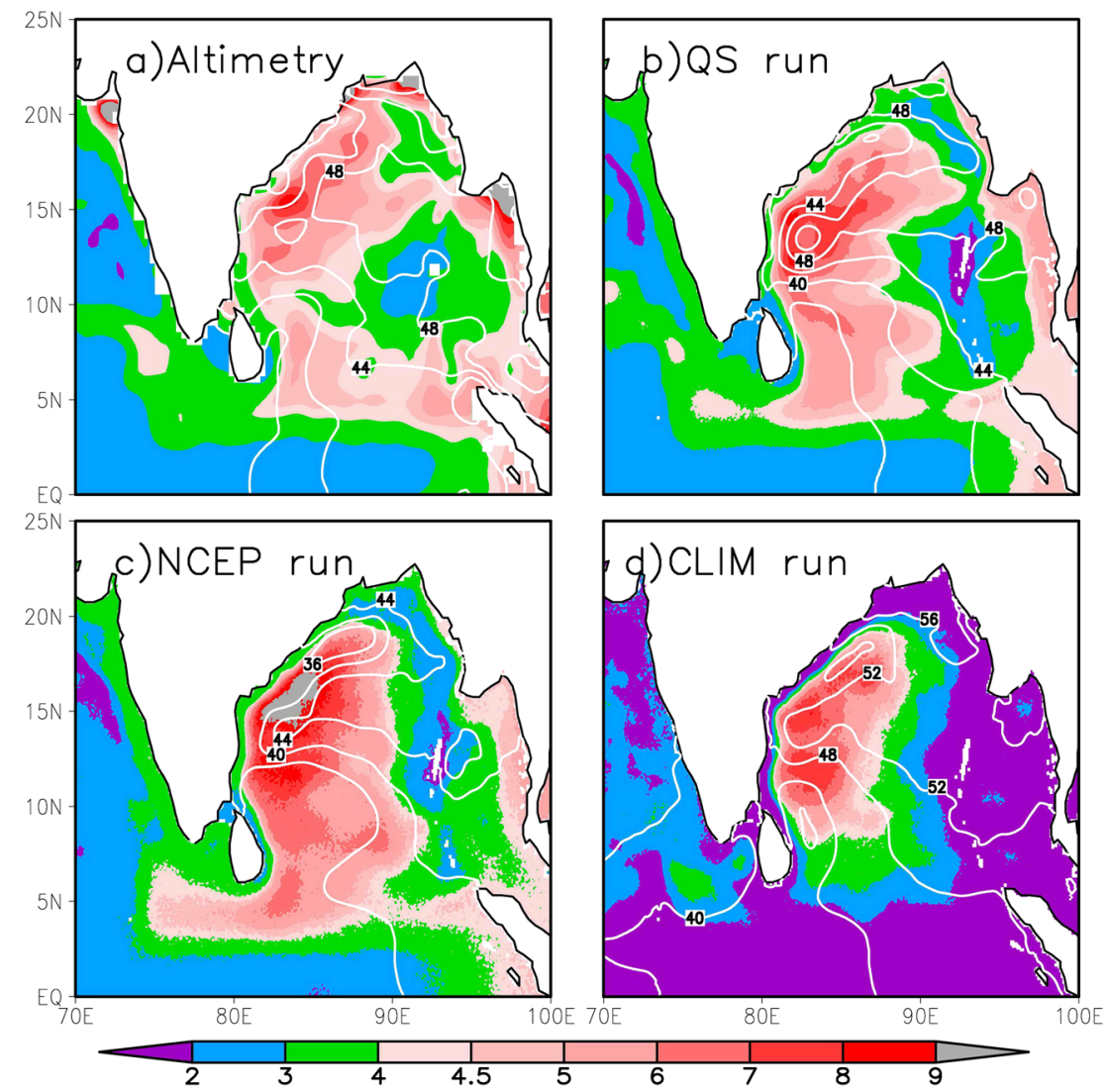

Figure 3. Annual mean standard deviation of the 30-120 day sea surface height (cm, color) and the mean sea surface height (white contours at $4 \mathrm{~cm}$ intervals) from the period 2000-2008 for (a) observations and the (b) OFES QSCAT, (c) NCEP, and (d) CLIM runs. 
circulation pattern in the BoB basin. High $\mathrm{SSH}$ is located in the eastern BoB, while low $\mathrm{SSH}$ is found in the western basin. The mean SSH values in the QSCAT, NCEP, and CLIM runs (Figures $3 \mathrm{~b}, 3 \mathrm{c}$, and $3 \mathrm{~d}$ ), which generally reproduce the observation, are characterized by a high $\mathrm{SSH}$ in the central basin. Among the three runs, the SSH pattern in the QSCAT run is the closest to observations.

[13] Figure 3a shows the standard deviations (STD) of the observed SSH ISV. The ISV is strong in the three regions: off the eastern and northern coasts of the BoB, in the western $\mathrm{BoB}$, and in a zonal band across the mouth of the BoB at $5^{\circ} \mathrm{N}$. These active ISV regions are simulated in the QSCAT and NCEP runs, except for three maximum ISV patches $(\mathrm{STD}>10 \mathrm{~cm})$ along the coast north of $15^{\circ} \mathrm{N}$, where the ISV is heavily influenced by river discharge from the Irrawaddy, Brahmaputra, Ganges, and Mahanadi Rivers. ISV and inter-annual variability of river discharge are not included in the model [Masumoto et al., 2004; Sasaki and Nonaka, 2006; Masumoto, 2010]. The ISV pattern in the NCEP run is smoother than that in the QSCAT run due to the low spatial resolution in the NCEP wind. In both observations and OFES model output, intraseasonal variance is weak in the vicinity of Andaman and Nicobar Islands.

[14] A similar agreement in basin-wide SSH structure is found for seasonal means between the observations (Figures $4 \mathrm{a}-4 \mathrm{~d}$ ) and model simulations (Figures $4 \mathrm{e}-4 \mathrm{~h}$ and 4i-41). The seasonal SSH patterns in the QSCAT run are very similar to observations, such as the basin-wide anticyclonic circulation during winter and the anticyclonic gyre in the western BoB during spring.

[15] SSH ISV over the BoB features considerable seasonality (Figure 4). In each season, the QSCAT run reproduces both observed mean and SSH ISV. In the western BoB, the ISV reaches its annual maximum in spring and minimum in winter, whereas southeast of Sri Lanka, it is relatively high in summer and autumn. Along $5^{\circ} \mathrm{N}$, a high ISV band extends from the northern tip of Sumatra to the south of Sri Lanka in spring. In the other three seasons, this high ISV band is less clear. In contrast to the other regions, ISV shows a weak seasonality along the eastern and northern coasts of the BoB.

\section{Origin of Intraseasonal Variability}

[16] Compared with the QSCAT and NCEP runs, the ISV in the CLIM run is weak in the whole basin (Figure 3). In the equatorial region and along the $\mathrm{BoB}$ coast, the reduction in ISV is especially large (from $5 \mathrm{~cm}$ to less than $2 \mathrm{~cm}$ ) throughout the year (Figures 4i-4l), indicating the importance of highfrequency atmospheric forcing. In contrast, in the western $\mathrm{BoB}$ variance remains high in the CLIM run, suggesting that high-frequency atmospheric forcing is less important there.

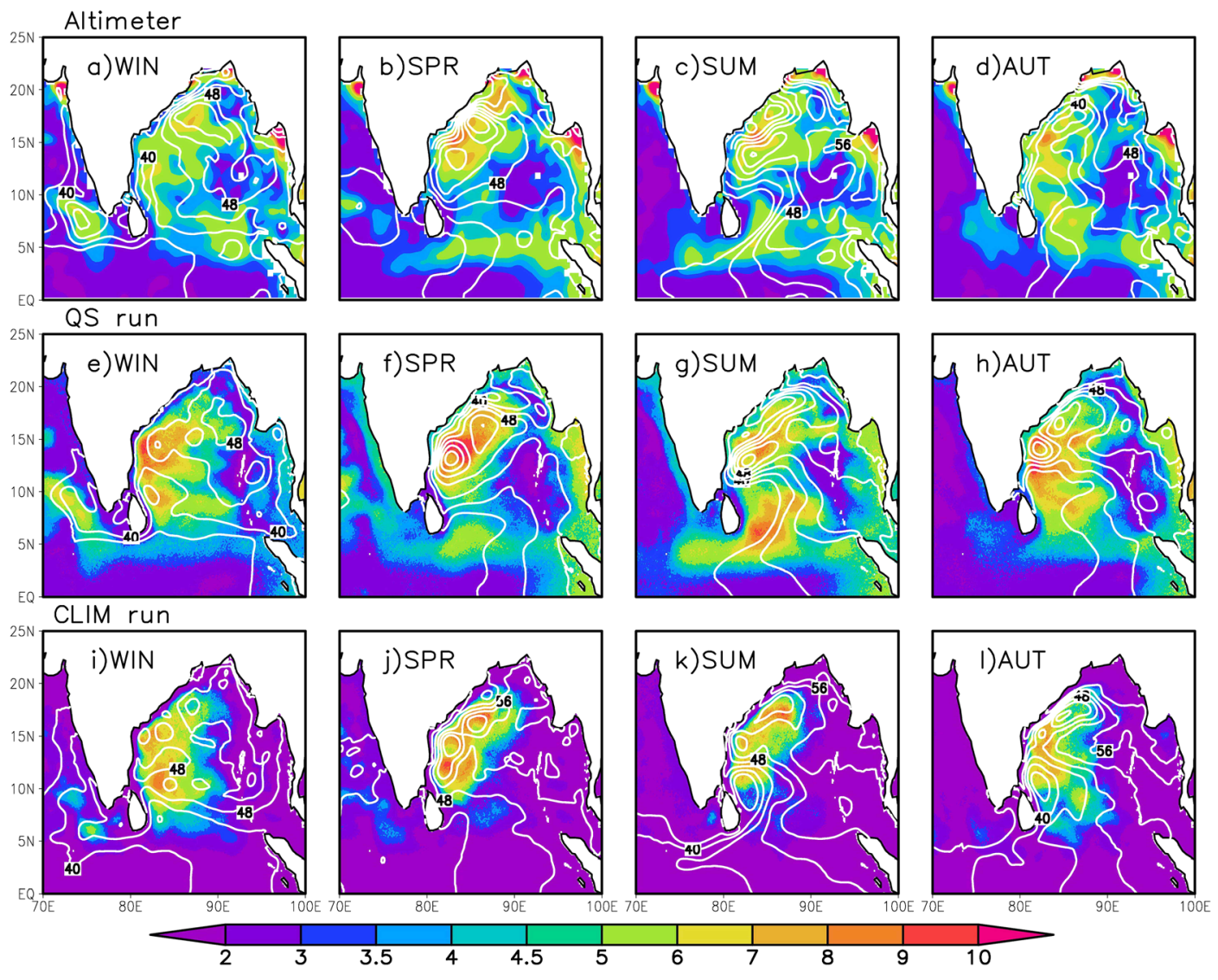

Figure 4. Seasonal mean standard deviation of the 30-120 day observed sea surface height (cm, color) and seasonal mean observed sea surface height (white contours at $4 \mathrm{~cm}$ intervals) for (a) winter (DJF), (b) spring (MAM), (c) summer (JJA), and (d) autumn (SON). (e-h) Same as Figures 4a-d, respectively, but for the QSCAT run. (i-l) Same as Figures $4 \mathrm{a}-\mathrm{d}$, respectively, but for the CLIM run. 
[17] Owing to the high resolution and accuracy of the QuikSCAT winds, the QSCAT run reproduces the spatial distribution of SSH ISV quite well. We take a further step to correlate the time series of observed and simulated intraseasonal SSH point-to-point in space. Figure 5 shows that the correlation between them is high along the equator, the eastern and northern coasts of the BoB, and the eastern coast of the Arabian Sea. In these regions, the correlation coefficients exceed 0.5 in all seasons, reaching a maximum in spring and summer. In the western $\mathrm{BoB}$, the point-to-point correlation is generally low. Regions with high correlation indicate the importance of high-frequency wind forcing, whereas low correlations suggest that other processes such as hydrodynamic instability may be important.

[18] In this section, we investigate the importance of highfrequency wind forcing, eddy activities, and instabilities of mean currents in individual regions. Section 4.1 describes propagation of the wind-driven equatorial Kelvin wave and its impact on the SSH ISV along the BoB coast. Section 4.2 presents the eddy activity and its effect on SSH ISV in the central BoB. Section 4.3 conducts an energetics analysis to discuss the instabilities of the mean currents.

\subsection{BoB Coast}

[19] To examine the origins of SSH variability along the $\mathrm{BoB}$ coast in detail, Figure 6 illustrates the evolution of observed wind stress and SSH, the patterns obtained by lagged regression to SSH off northern Sumatra. Easterly wind anomalies over the central and eastern equatorial IO lead to a region of low SSH in the eastern IO at 35 days; at this time, a downwelling-favorable equatorial Rossby wave is present from $5^{\circ} \mathrm{S}-5^{\circ} \mathrm{N}$ to $75^{\circ}-85^{\circ} \mathrm{E}$, and an upwellingfavorable coastal Kelvin wave has propagated northward along the eastern coast of the $\mathrm{BoB}$ (Figures 6a-6c). When equatorial wind switches from easterly to westerly, it drives a downwelling equatorial Kelvin wave that propagates to Sumatra, where it reflects as a Rossby wave and hence raises SSH markedly (Figures 6c-6e). Subsequently, the high SSH signal propagates around the $\mathrm{BoB}$ coast as a coastal wave. Note that there are northeasterly alongshore winds off the northeast coast of India, which can strengthen the coastal signal there (Figures 6e-6h). At the tip of Sri Lanka, the coastal wave meets the westward Rossby wave and then propagates northwestward along the west coast of the Indian peninsula (Figures $6 \mathrm{~g}-6 \mathrm{i}$ ). A similar result is obtained when we apply the analysis to the output from the QSCAT run (not shown). The good agreement between observations and the QSCAT simulation along the coast regions indicates the utility of satellite altimetry over shallow waters with weak tidal aliasing.

[20] Figure 7c shows a lag regression of observed intraseasonal SSH along the equatorial/coastal waveguide in Figure 7a. The SSH signal propagates eastward as a Kelvin wave along the equator and strengthens significantly when it reaches the coast of Sumatra. The SSH signal intensifies because of the reflected Rossby wave. Essentially the water that flows into the coast piles up there, since the coast brings it to zero. That pile up continues until the packet of Rossby waves begins to propagate offshore. When the wave crosses the northern tip of Sumatra (at about $5^{\circ} \mathrm{N}$ ), its amplitude decreases markedly, apparently due to the part of the signal's energy that is reflected into equatorial Rossby waves. The signal then increases in magnitude once more as it propagates northward. The local alongshore wind forcing acts to amplify the wave (Figure 6f), and so does the shoaling mean thermocline. The wave has another decrease in amplitude
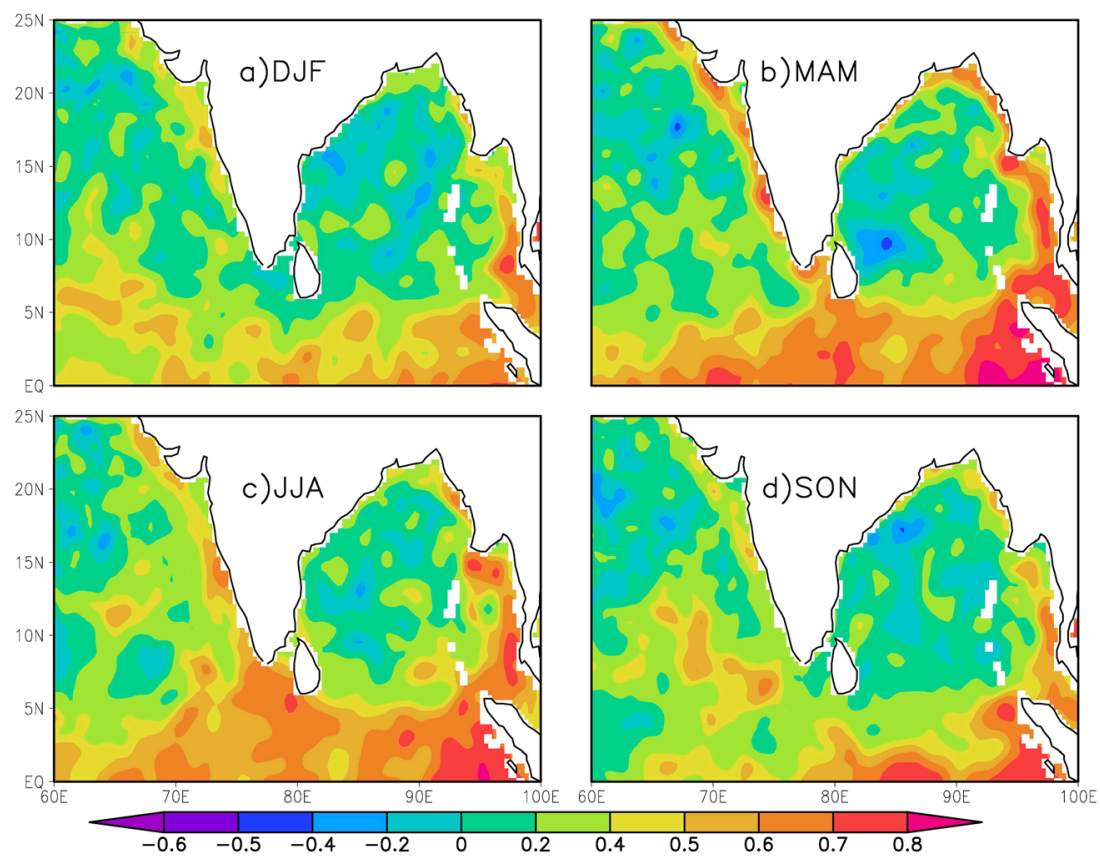

Figure 5. Point-to-point correlation coefficients between the 30-120 day sea surface height from altimetric observation and the QSCAT run for (a) winter, (b) spring, (c) summer, and (d) autumn. DJF, December-January-February; MAM, March-April-May; JJA, June-July-August; SON, September-October-November. 

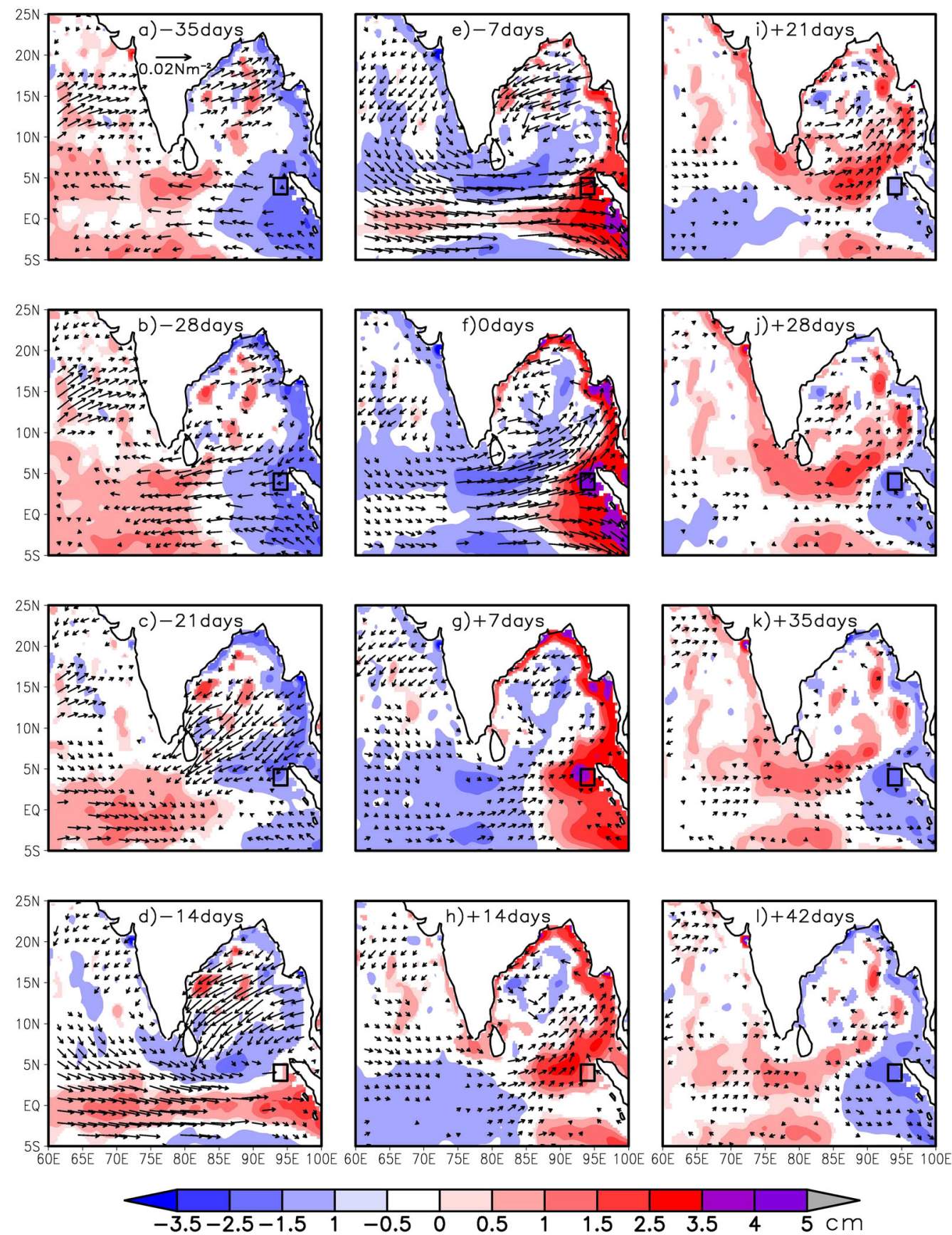

Figure 6. Regression of the 30-120 day observed sea surface height (cm) and QuikSCAT wind stress to the normalized $30-120$ day sea surface height within the black box $\left(93^{\circ}-95^{\circ} \mathrm{E}, 3^{\circ}-5^{\circ} \mathrm{N}\right)$. Patterns leading by $35,28,21,14$, and 7 days and lagging by $7,14,21,28,35$, and 42 days are shown.

when it turns a sharp corner at the tip of the Irrawaddy Delta $\left(95^{\circ} \mathrm{E}, 16^{\circ} \mathrm{N}\right)$ off Myanmar (station 46 in Figure $\left.7 \mathrm{a}\right)$. The reason for this decrease is discussed in section 4.2. The estimated wave phase speed along the waveguide is about $2.65 \mathrm{~m} / \mathrm{s}$, consistent with the estimated wave phase speed of a first baroclinic mode in the region $(2.6-2.8 \mathrm{~m} / \mathrm{s})$ [Chelton et al., 1998]. The QSCAT run simulates the observed wave propagation along the waveguide quite well, including the locations of the wave amplitude decreases (Figure 7d) and the phase speed of the coastal wave $(2.60 \mathrm{~m} / \mathrm{s})$.

[21] At $5^{\circ} \mathrm{N}$, part of the energy is reflected from the coastal area into the interior ocean as westward-propagating Rossby waves (Figure 8a). The observed 30-120 day SSH signal propagates westward from the coast and reaches $74^{\circ} \mathrm{E}$ in 36 days with a mean phase speed of about $0.74 \mathrm{~m} / \mathrm{s}$. This phase speed is in good agreement with the first internal-mode Rossby wave speed in this region, which is $0.68-0.77 \mathrm{~m} / \mathrm{s}$ [Webber et al., 2010]. A similar Rossby wave is present in the QSCAT run with a phase speed of the Rossby wave about $0.71 \mathrm{~m} / \mathrm{s}$ (Figure 8b).

[22] According to the theory of Clarke and Shi [1991], poleward-propagating Kelvin waves at a given period can radiate offshore as Rossby waves equatorward of a critical latitude. Poleward of this latitude, the Kelvin waves remain 

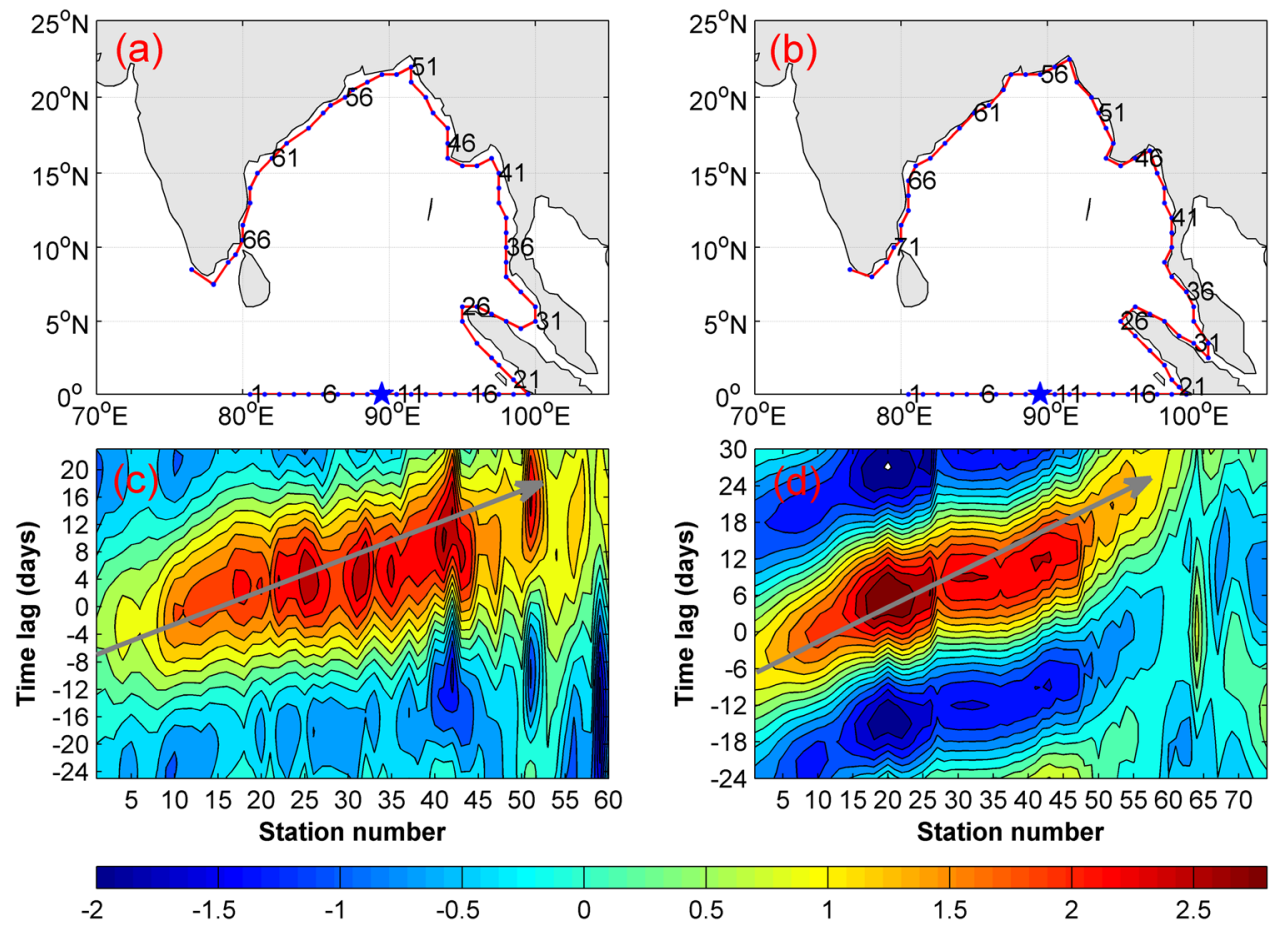

Figure 7. (a) Distribution of $1^{\circ}$ boxes along the BoB coast. (c) Corresponding time-station lag regression of the observed intraseasonal sea surface height $(\mathrm{cm})$ with respect to the normalized intraseasonal sea surface height at the stations indicated by blue stars. (b and d) Same as Figures 7a and 7c, except for the QSCAT run data.

(a)



(b)



Figure 8. (a) Time-longitude lag regression of the observed 30-120 day intraseasonal SSH (cm) along $5^{\circ} \mathrm{N}$ starting at $95^{\circ} \mathrm{E}$. (b) Same as Figure 8a, except for the QSCAT run.

coastally trapped. For example, the theoretical critical latitude for 40-60 day Rossby waves is about $10^{\circ}$. At that latitude, the regression coefficient of the 40-60 day SSH decreases offshore dramatically (Figure 9a); furthermore, the across-shore structure of SSH is very similar to the free surface height structure induced by a traveling Kelvin wave in a channel [Pedlosky, 2003]. Thus, south of $10^{\circ} \mathrm{N}$, a part of the signal's energy propagates westward (Figure 9c). North of $10^{\circ} \mathrm{N}$, the signal propagates northward as a trapped coastal Kelvin wave. Similarly, for the 100-120 day SSH signal, the critical latitude is about $15^{\circ} \mathrm{N}$. Consistent with this value, the SSH signal radiates offshore as a Rossby wave south of $15^{\circ} \mathrm{N}$, as indicated by the westward-propagating sea-level signal south of $15^{\circ} \mathrm{N}$ in Figures $6 \mathrm{~h}-6 \mathrm{j}$ and Figure 9d, but remains coastally trapped north of that latitude (Figure 9b).

\subsection{Central BoB}

[23] We detect and track eddies based on intraseasonal anomalies of observed and simulated SSH during 2000-2008. To define eddies, we use a criterion based on the existence of closed SSH contours [Wang et al., 2003]. Specifically, let 

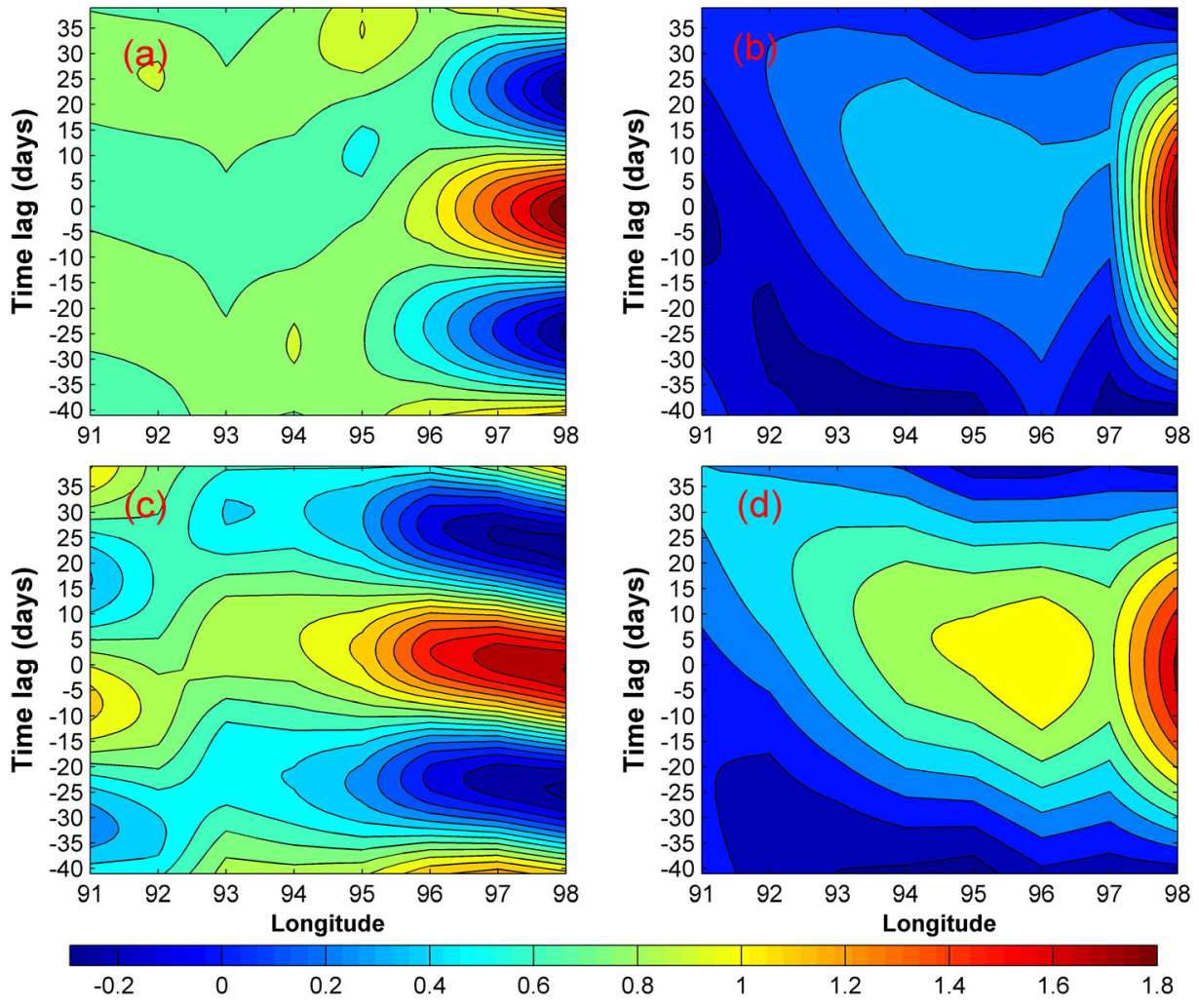

Figure 9. (a and c) Time-longitude lag regression of the observed 40-60 day intraseasonal SSH $(\mathrm{cm})$ along $10^{\circ} \mathrm{N}$ and $8^{\circ} \mathrm{N}$ starting at $98^{\circ} \mathrm{E}$. (b and d) Time-longitude lag regression of the 100-120 day intraseasonal sea surface height $(\mathrm{cm})$ along $15^{\circ} \mathrm{N}$ and $13^{\circ} \mathrm{N}$ starting at $98^{\circ} \mathrm{E}$.

SLA $_{\text {dif }}$ be the absolute value of the SSH difference between its value on the outermost closed contour and the relative maximum or minimum inside the enclosed region. Then, we define the enclosed region to be an eddy provided that $\mathrm{SLA}_{\mathrm{dif}} \geq 4.0 \mathrm{~cm}$.

[24] All eddies with $\mathrm{SLA}_{\mathrm{dif}} \geq 4.0 \mathrm{~cm}$ are identified in initial maps at time $t_{0}$. We then search for the same eddy from its initial position in the next map at time $t_{0}+7$ days. Figure 10 shows the tracks of anticyclonic and cyclonic eddies that last more than 1 month. Generally, there are more cyclonic eddies than anticyclonic eddies. Two southwestslanted eddy pathways are found in the western BoB. The pathways are especially distinct for anticyclonic eddies. One pathway is located near the western boundary, the other is in the interior Bay, and each is associated with a local maximum of $\mathrm{SSH}$ variance. In the two pathways, most eddies propagate southwestward (Figures 10a and 10b). High eddy occurrence can also be found in the western BoB in the QSCAT run; however, in the model more eddies occur near the western boundary than in the interior Bay, and the two-band structure is not clear.

[25] Figure 11 shows the evolution of eddies along the track in the interior BoB. The downwelling Kelvin wave from the equator reaches the eastern coast of $\mathrm{BoB}$ and turns a sharp corner at the tip of the Irrawaddy Delta off Myanmar $\left(95^{\circ} \mathrm{E}, 16^{\circ} \mathrm{N}\right)$. After the Kelvin wave passes the delta, an anticyclonic eddy forms and then propagates southwestward (Figures 11b-11e). Likewise, following an upwelling Kelvin wave, a cyclonic eddy forms at lag 21 days and propagates southwestward, forming an eddy train with the preceding anticyclonic eddy (Figures $11 \mathrm{f}-11 \mathrm{k}$ ).

[26] Figure 12 shows that part of the energy radiates southwest along the interior eddy track from the coast as it turns the corner, which explains the decrease of coastal wave amplitude there (Figures $7 \mathrm{~b}$ and $\mathrm{d}$ ). The pathway of the eddies matches very well with the weak maximum in $\mathrm{SSH}$ variance in the central $\mathrm{BoB}$, indicating that eddy shedding events contribute to the high SSH ISV in the central BoB. A similar southwestward eddy shedding has been linked to coastal wave propagation off Central America in the northeast Pacific [Zamudio et al., 2006; Chang et al., 2012]. The fluctuations in local winds play an important role.

\subsection{Western BoB}

[27] Extensive work exists on the eddy-flow interaction and energy conversion [e.g., Lorenz, 1955; Böning and Budich, 1992; Eden and Böning, 2002]. Ferrari and Wunsch [2009] gave a review on the reservoirs, sources, and sinks of ocean circulation kinetic energy. Using the QSCAT run, we perform an energetics analysis in the BoB following Böning and Budich [1992]. Eddy kinetic energy (EKE) and available eddy potential energy (EPE) per unit mass are calculated as follows:

$$
\begin{gathered}
\mathrm{EKE}=\frac{1}{2}\left(u^{\prime 2}+v^{\prime 2}\right), \\
\mathrm{EPE}=-\frac{g \widetilde{\rho}^{2}}{2 \rho\left(\partial \bar{\rho}_{\theta} / \partial z\right)},
\end{gathered}
$$



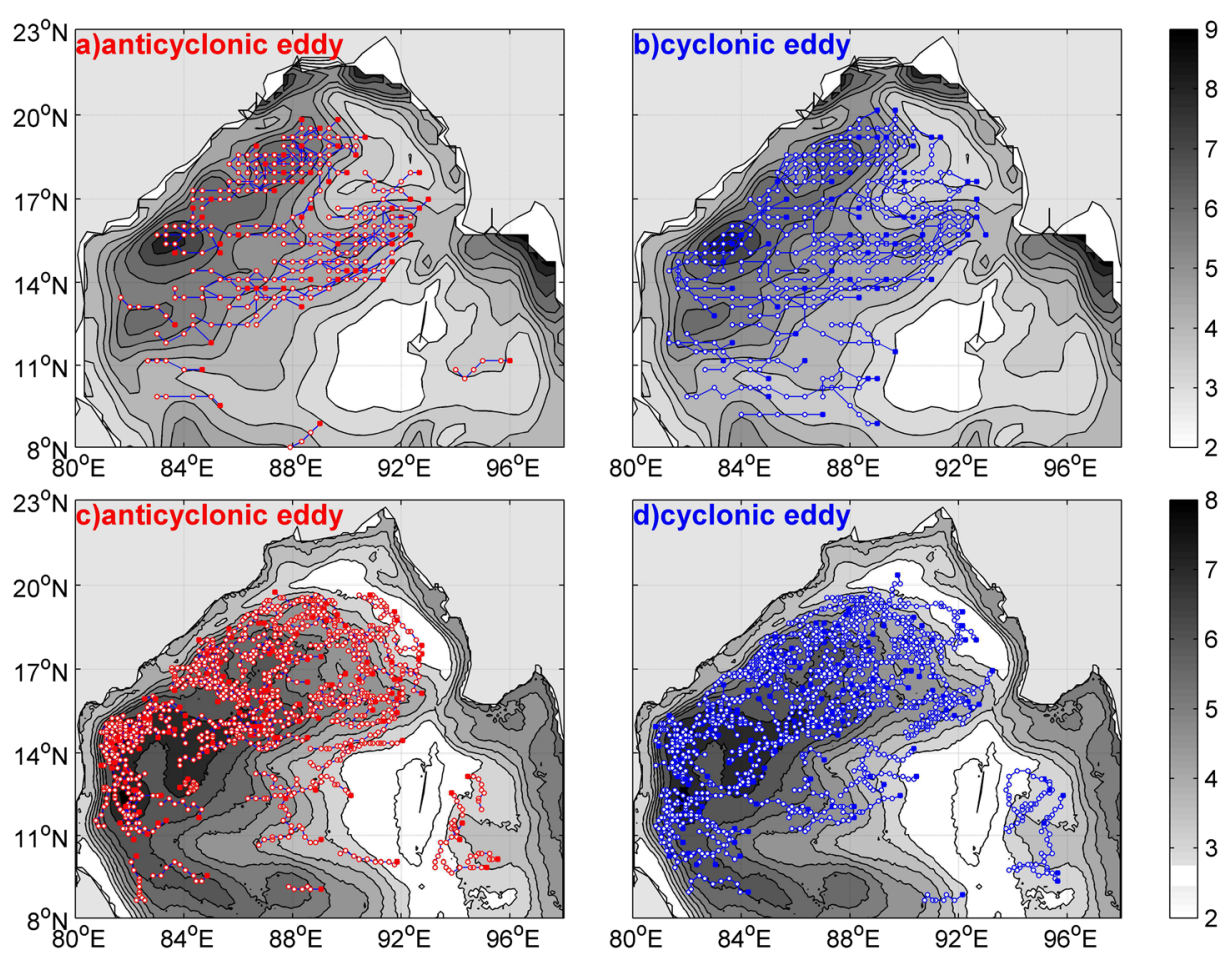

Figure 10. Tracks of (a) anticyclonic and (b) cyclonic eddies that last more than 30 days and annual mean STD of intraseasonal surface height (grayscale, $\mathrm{cm}$ ) derived from altimetry data during 2000-2008. (c and d) Same as Figures 10a and 10b, respectively, except that for the QSCAT run.

where $\widetilde{\rho}(x, y, z, t)=\rho(x, y, z, t)-\rho_{b}(z), \rho_{b}(z)$ is a background density profile taken as the annual and horizontal mean within the $\mathrm{BoB}$, and $\bar{\rho}_{\theta}(z)$ is the annual and horizontal mean potential density. Transient components of velocity and density are defined as variability at periods of 30-120 days, and the residual low-frequency variations are treated as the basic state. A growing eddy draws potential and kinetic energy from the mean flow. The conversion from mean potential energy (MPE) to EPE through baroclinic instability is defined as

$$
T 2=-\frac{g}{\rho\left(\partial \rho_{\theta} / \partial z\right)}\left(u^{\prime} \widetilde{\rho}^{\prime} \frac{\partial \overline{\bar{\rho}}}{\partial x}+v^{\prime} \widetilde{\rho}^{\prime} \frac{\partial \overline{\bar{\rho}}}{\partial y}\right)
$$

and the barotropic conversion of mean kinetic energy (MKE) to EKE is given by

$$
T 4=-\left(u^{\prime} u^{\prime} \frac{\partial \bar{u}}{\partial x}+u^{\prime} v^{\prime}\left(\frac{\partial \bar{v}}{\partial x}+\frac{\partial \bar{u}}{\partial y}\right)+v^{\prime} v^{\prime} \frac{\partial \bar{v}}{\partial y}\right)
$$

[28] Positive values of T2 (T4) indicate baroclinic (barotropic) instability.

[29] Vertically integrated EKE is high in the southwestern $\mathrm{BoB}$ and along the equator, whereas high EPE is found in the western BoB (Figures 13a and b). Comparing Figure 13b against Figure 13c, EPE dominates the total eddy energy (TEE, sum of EKE and EPE). Figure 14 shows the seasonal distribution of TEE and the sum of $T 2$ and $T 4(T 2+T 4)$. To the east of Sri Lanka, TEE reaches its maximum during summer due to instability of the SMC. Along the western boundary of $\mathrm{BoB}$, high TEE and positive $T 2+T 4$ are found. The TEE is highest in autumn in this region.

[30] Figure 15a shows the seasonal cycle of eddy energy and the energy conversion rate in the western boundary region. In this region, TEE is low from January to July $\left(20 \sim 40 \times 10^{6} \mathrm{~cm}^{3} / \mathrm{s}^{2}\right)$ and peaks in autumn (about $60 \times 10^{6} \mathrm{~cm}^{3} / \mathrm{s}^{2}$ ). A time series of $T 2$ has similar variations to TEE. During July-December, $T 2$ is positive, indicative of the MPE conversion to EPE through baroclinic instability. The correlation between TEE and $T 2$ (T4) is $0.91(-0.11)$. The larger amplitude of $T 2$ and its high correlation with TEE implies that baroclinic instability is the dominant source of eddy energy along the western boundary. To the east of Sri Lanka, TEE peaks in summer (June-August) and is low during spring and winter. The correlation between TEE and T2 (T4) is 0.11 (0.51) when $T 2$ (T4) leads TEE by 9 days, indicating that barotropic instability may be important in this region (Figure 15b). In summer, the SMC flows eastward and turns northward after passing Sri Lanka [Schott and McCreary, 2001]. In June, $T 2+T 4$ is negative, indicating that the eddy energy transfers to the SMC and accelerates the mean current. During July-August, T2 $+T 4$ becomes positive. The instability of SMC converts mean energy to eddy energy. The baroclinic energy conversion $T 2$ is large in regions of high $\mathrm{SSH}$ variance along the western boundary of the BoB (Figures $4 \mathrm{e}-4 \mathrm{~h}$ ), indicative of the importance of baroclinic instabilities. This result is consistent with the CLIM run where $\mathrm{SSH}$ variance remains high in the western $\mathrm{BoB}$ despite the lack of intraseasonal forcing (Figures 3 and 4). 

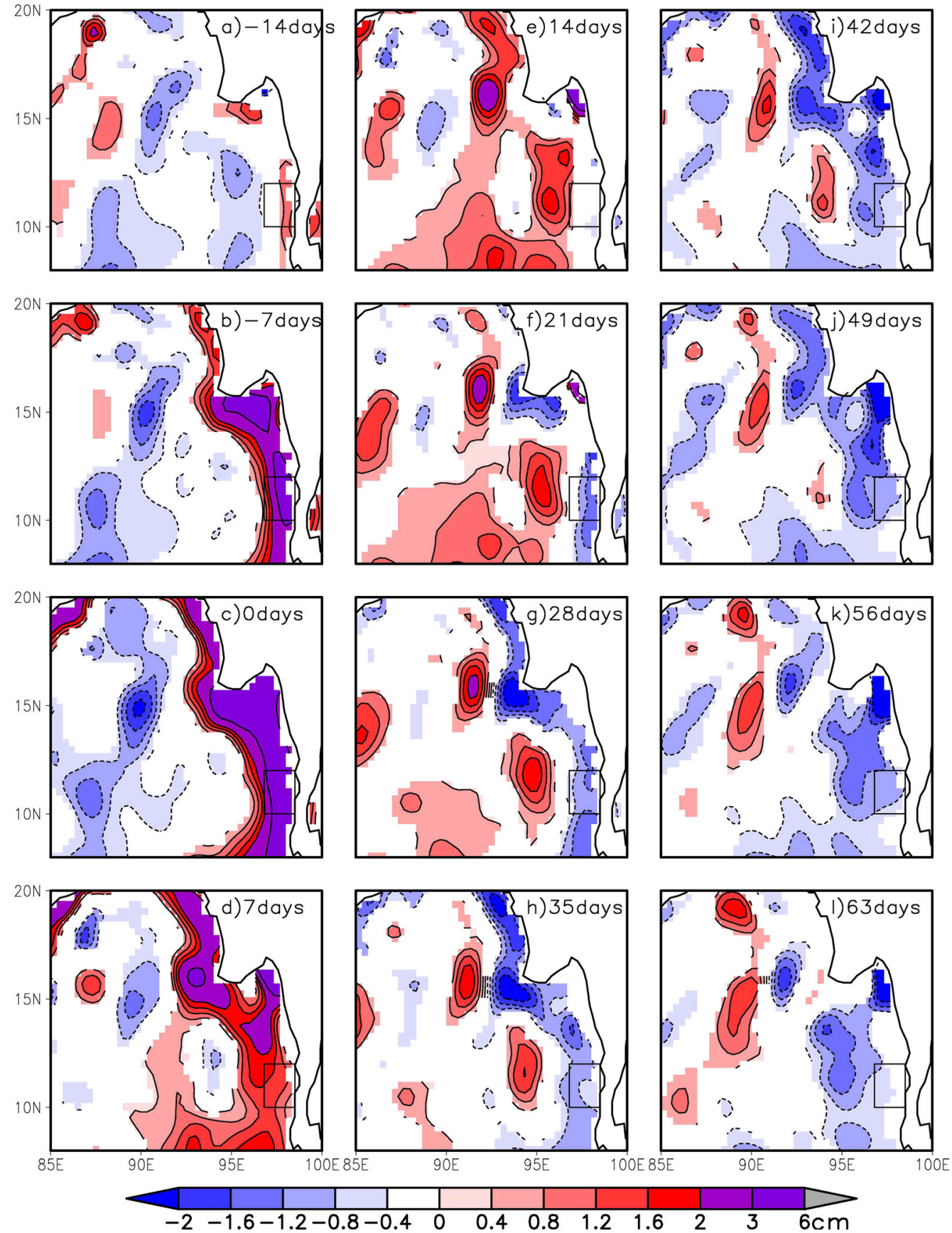

Figure 11. Regression of the 30-120 day observed sea surface height $(\mathrm{cm})$ to the normalized 30-120 day filtered sea surface height within the black box $\left(96.5^{\circ}-98.5^{\circ} \mathrm{E}, 10^{\circ}-12^{\circ} \mathrm{N}\right)$.

[31] Several factors account for the evolution of instabilities, including the mean flow shear and ocean stratification. For example, Figure 16 shows stronger vertical shear of zonal velocity to the east of Sri Lanka during summer, whereas the stratification is similar throughout the year. So, the vertical shear of zonal velocity accounts for the larger amplitude of $T 2$ during summer. The terms $-\left(u^{\prime} u^{\prime} \frac{\partial \bar{u}}{\partial x}+u^{\prime} v^{\prime} \frac{\partial \bar{u}}{\partial y}\right)$ dominate $T 4$ variations $(r=0.69)$. Specifically, the horizontal shear of the zonal current is responsible for the large $T 4$ during summer in this region (Figure 17). During June-August, $-\left(u^{\prime} v^{\prime} \frac{\partial \bar{v}}{\partial x}+v^{\prime} v^{\prime} \frac{\partial \bar{v}}{\partial y}\right)$ is negative (Figure 17) and the meridional current is intensified
(Figure 18), indicating an eddy kinetic energy transfer to the SMC that accelerates the meridional current. In contrast, $-\left(u^{\prime} u^{\prime} \frac{\partial \bar{u}}{\partial x}+u^{\prime} v^{\prime} \frac{\partial \bar{u}}{\partial y}\right)$ is positive and the zonal current decreases from June to August, indicating the conversion of mean kinetic energy to eddy kinetic energy (Figure 18). The negative $T 4$ during June is mainly caused by $-\left(u^{\prime} v^{\prime} \frac{\partial \bar{v}}{\partial x}+v^{\prime} v^{\prime} \frac{\partial \bar{v}}{\partial y}\right)$.

\section{Conclusions and Discussion}

[32] We have studied SSH ISV in the BoB, using altimetry data and OFES model output. The SSH ISV has large 
a)

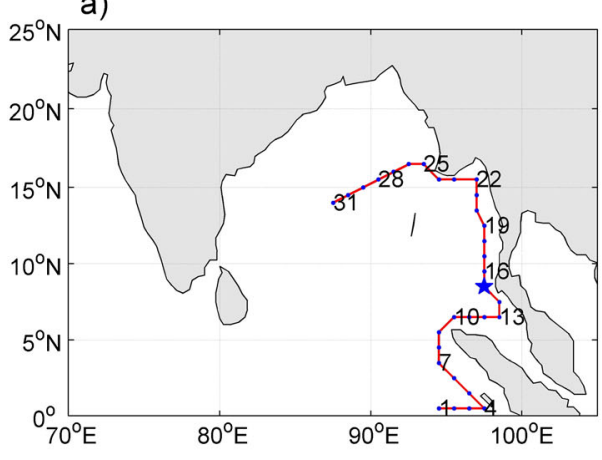

b)

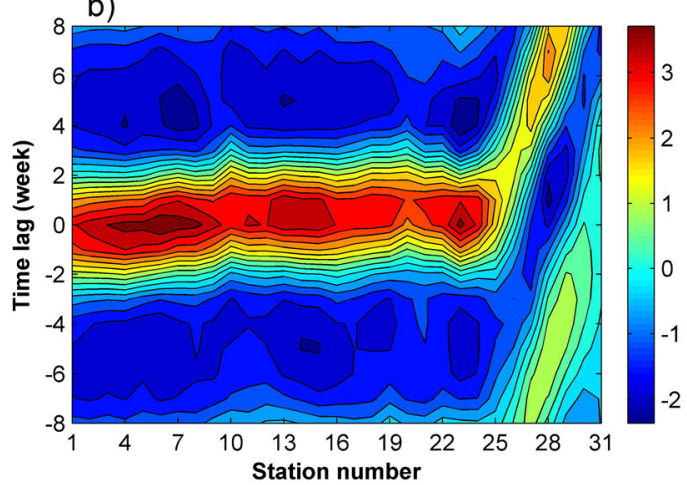

Figure 12. (a) Distribution of $1^{\circ}$ boxes along the BoB coast. (b) Corresponding time-station lag regression of the observed intraseasonal sea surface height $(\mathrm{cm})$ with respect to the normalized intraseasonal sea surface height at the station indicated by the blue star.
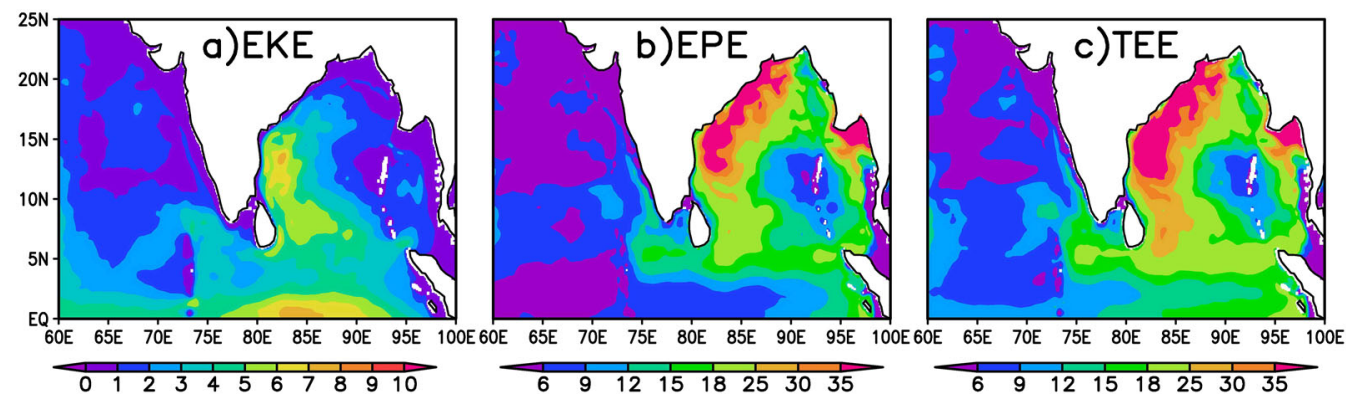

Figure 13. Annual mean vertically integrated eddy kinetic energy (EKE), eddy potential energy (EPE), and total eddy energy (TEE; $\times 10^{6} \mathrm{~cm}^{3} / \mathrm{s}^{2}$ ) derived from the QSCAT run.

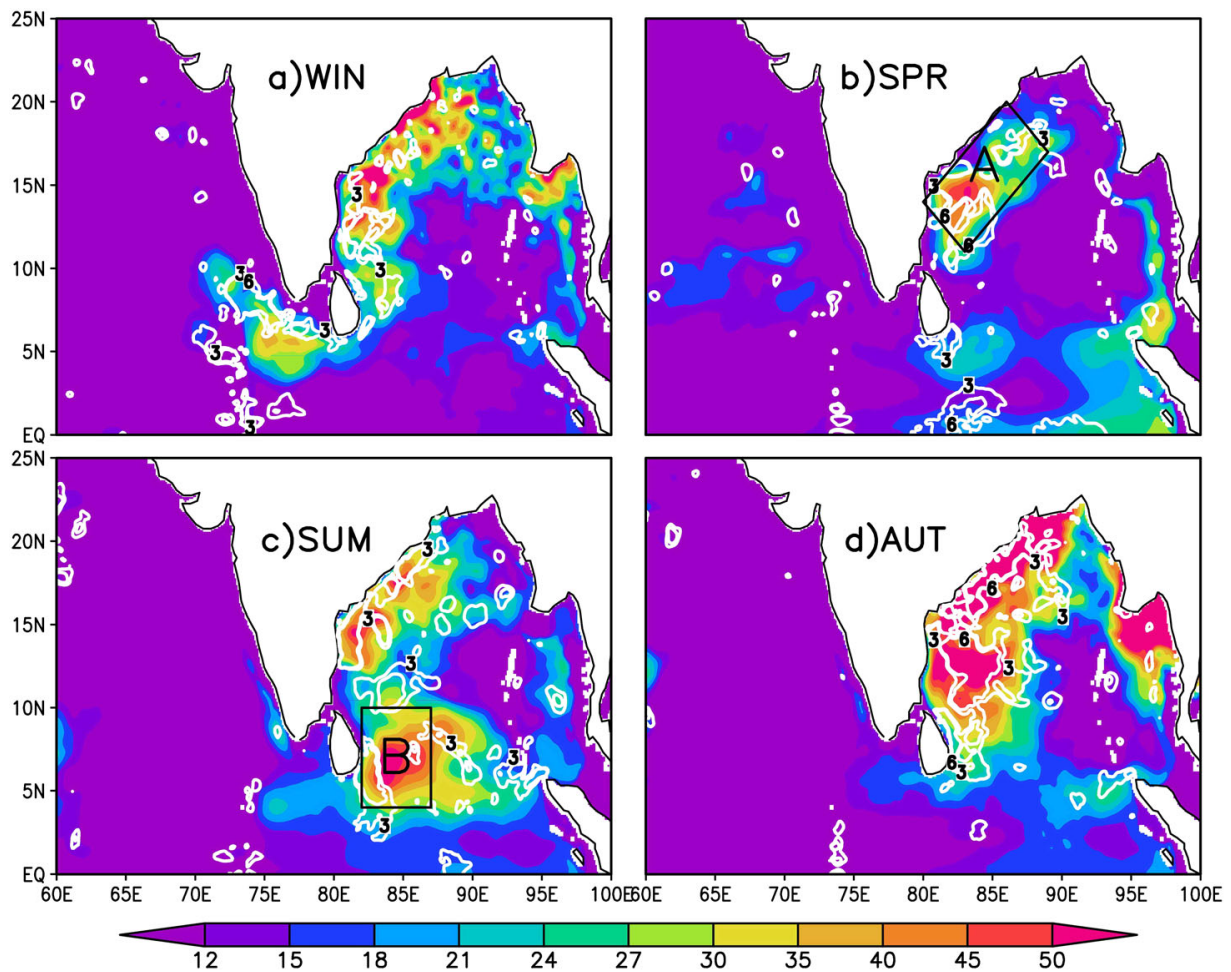

Figure 14. Seasonal mean vertically integrated total eddy energy (TEE; $\times 10^{6} \mathrm{~cm}^{3} / \mathrm{s}^{2}$, color) and the sum of $T 2$ and $T 4$ (white contours at 3 and $6 \mathrm{~cm}^{3} / \mathrm{s}^{3}$ ) derived from the QSCAT run for (a) winter (DJF), (b) spring (MAM), (c) summer (JJA), and (d) autumn (SON). 
amplitudes along the eastern and northern coasts of the BoB, in the western $\mathrm{BoB}$, and in a zonal band along $5^{\circ} \mathrm{N}$ and is weak in the vicinity of Andaman and Nicobar Islands. It exhibits a clear seasonality, related to the annual cycle of the monsoons in the BoB.

[33] Point-to-point correlations of SSH between observations and the OFES QSCAT simulation are high in the equatorial region and along the eastern and northern coasts of the $\mathrm{BoB}$, indicating the importance of intraseasonal wind forcing in these regions. Forced by intraseasonal wind, the equatorial Kelvin wave propagates eastward and reaches the western
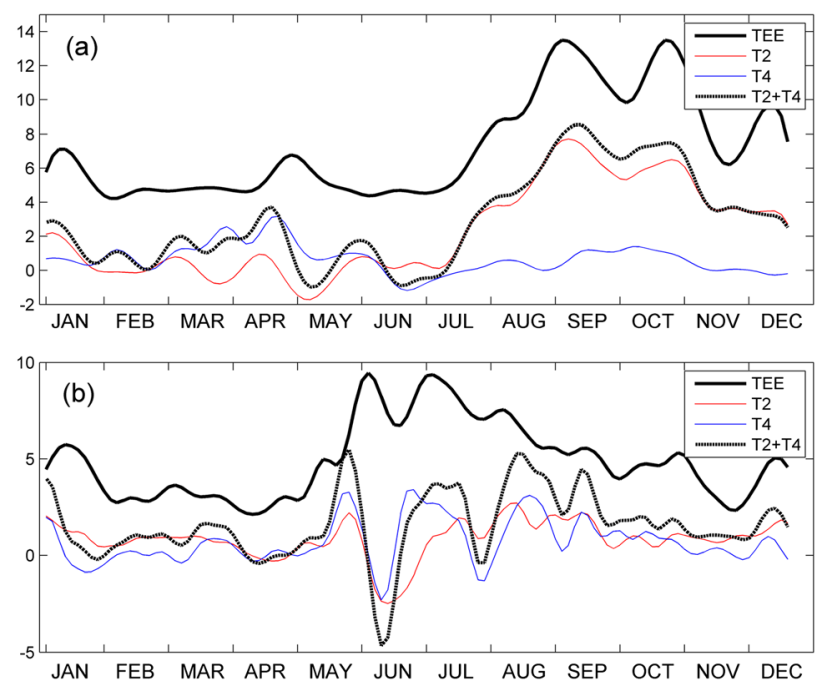

Figure 15. The 3 day climatological mean of total eddy energy (TEE; $5 \times 10^{6} \mathrm{~cm}^{3} / \mathrm{s}^{2}$ ) and the sum of $T 2$ and $T 4$ $\left(T 2+T 4 ; \mathrm{cm}^{3} / \mathrm{s}^{3}\right)$ averaged in (a) the western boundary of $\mathrm{BoB}$ (region A in Figure 14b) and (b) east of Sri Lanka (region B in Figure 14c).

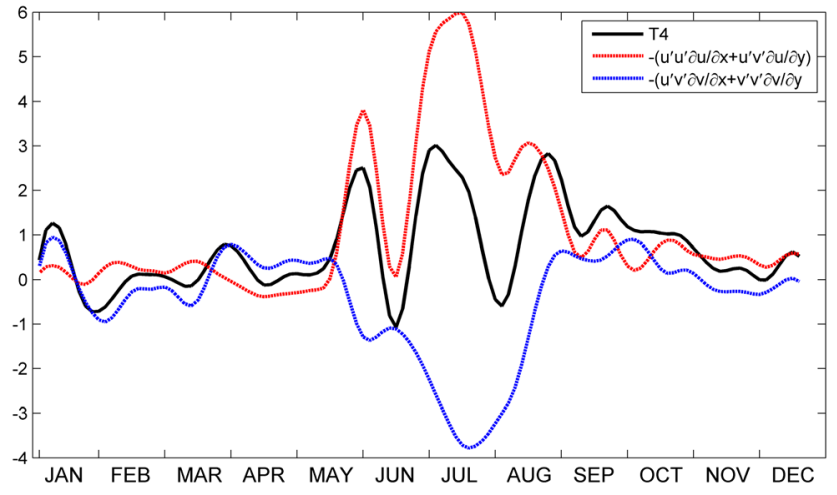

Figure 17. The 3 day climatological mean of $T 4\left(\mathrm{~cm}^{3} / \mathrm{s}^{3}\right)$, $-\left(u^{\prime} u^{\prime} \frac{\partial \bar{u}}{\partial x}+u^{\prime} v^{\prime} \frac{\partial \bar{u}}{\partial y}\right)$ and $-\left(u^{\prime} v^{\prime} \frac{\partial \bar{v}}{\partial x}+v^{\prime} v^{\prime} \frac{\partial \bar{v}}{\partial y}\right)$ averaged in the region to the east of Sri Lanka (region B in Figure 14c).

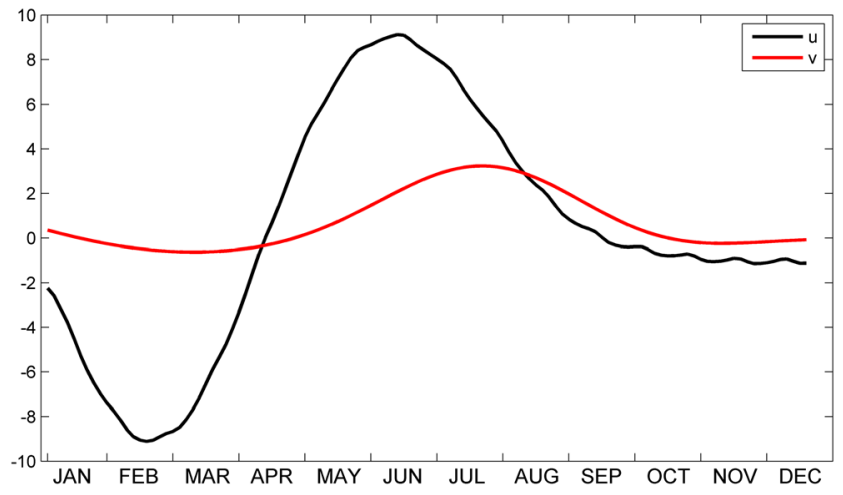

Figure 18. The 3 day climatological mean of zonal $(\mathrm{cm} / \mathrm{s}$, black curve) and meridional $(\mathrm{cm} / \mathrm{s}$, red curve) velocities averaged in the upper $200 \mathrm{~m}$ in the region to the east of Sri Lanka (region B in Figure 14c).

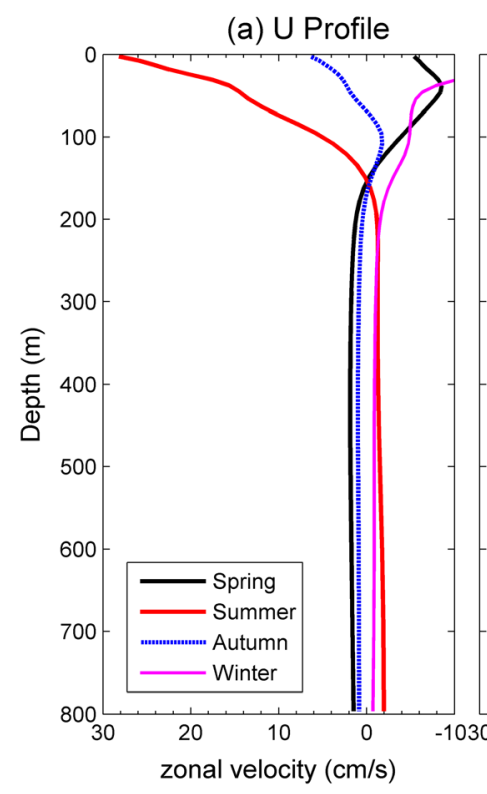

(b) V Profile

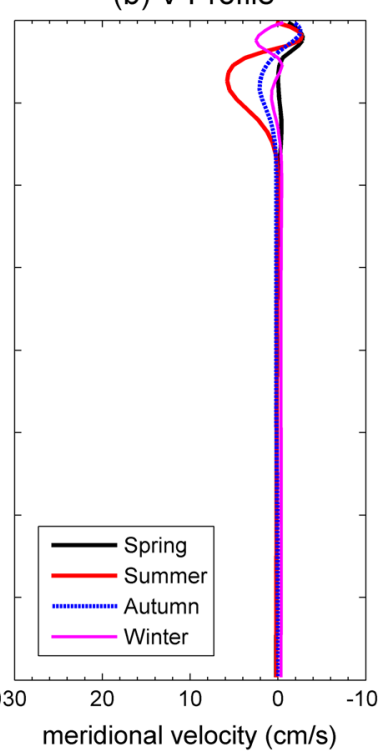

(c) BFS

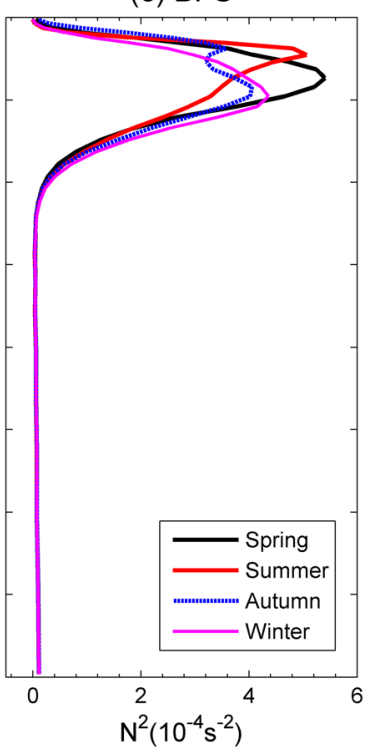

Figure 16. (a) Seasonal mean zonal velocity profile, (b) seasonal mean meridional velocity profile, and (c) the square of the buoyancy frequency, averaged within the black box in Figure $14 \mathrm{c}$ from the QSCAT run. 


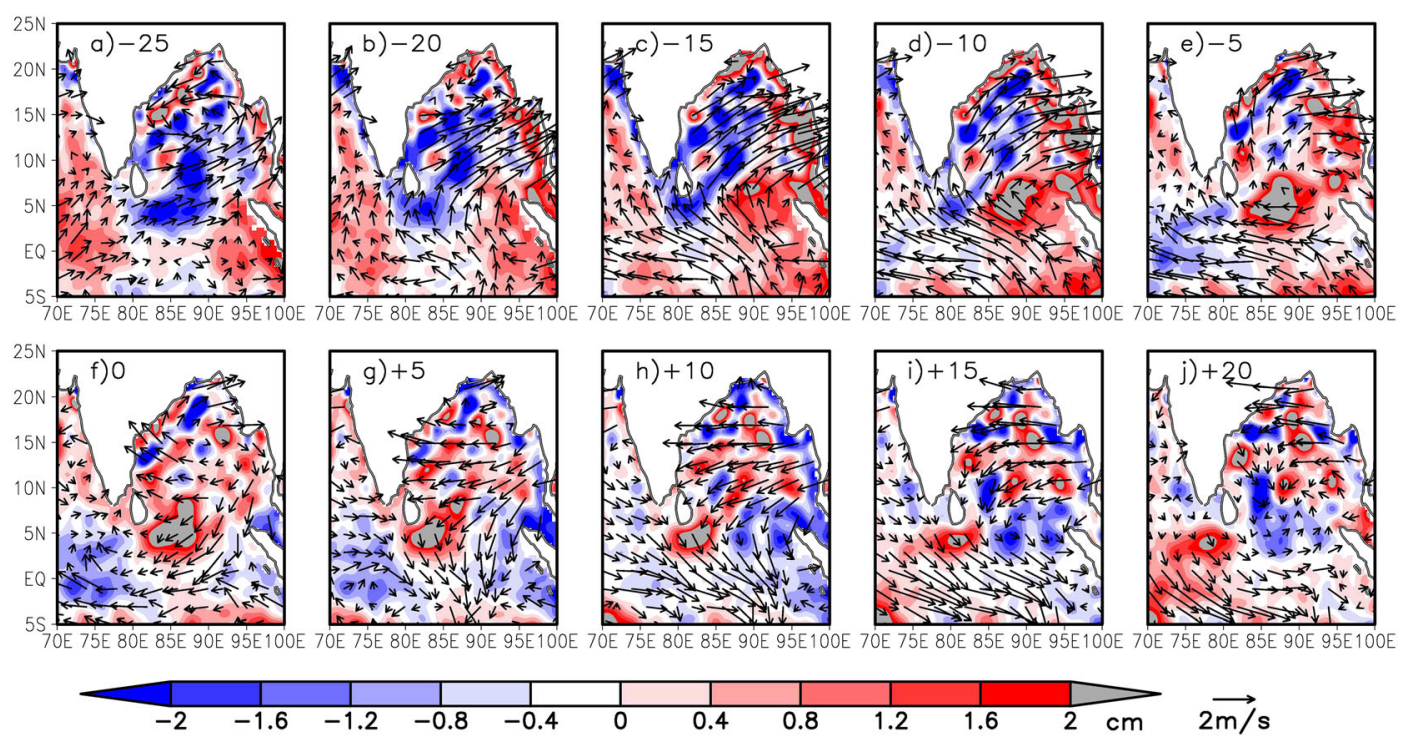

Figure 19. Composite anomalies of the $(a-j)$ summer observed sea surface height (cm, color) and QuickSCAT surface wind (vector) at lags $-25,-20,-15,-10,-5,0,5,10,15$, and 20 days relative to phase 1 of the MJO defined by Wheeler and Hendon [2004]. The days when the Wheeler and Hendon index exceeds a threshold value of 1.5 are used.

coast of Sumatra, where it reflects as a northward-propagating coastal wave along the BoB coast. The coastal wave contributes to SSH ISV along the eastern and northern coasts. The equatorial intraseasonal wind also drives equatorial Rossby waves between $5^{\circ} \mathrm{N}$ and $5^{\circ} \mathrm{S}$. Directly wind-forced Rossby waves, as well as Rossby waves radiating from the northern tip of Sumatra, cause the enhanced SSH ISV along $5^{\circ} \mathrm{N}$. The wave propagation captured by regression analysis is consistent with previous studies [e.g. Oliver and Thompson, 2010; Webber et al., 2010, 2012]. This study reveals new features of the costal wave. The equatorial Kelvin wave propagates eastward along the equator and strengthens significantly when it propagates from the coast of Sumatra. When the wave crosses the northern tip of Sumatra, its amplitude decreases markedly, apparently due to the part of the signal's energy that is reflected into equatorial Rossby wave. The wave has another decrease in amplitude when it turns a sharp corner at the tip of the Irrawaddy Delta off Myanmar. Our results show that $10^{\circ} \mathrm{N}$ and $15^{\circ} \mathrm{N}$ are the critical latitudes for the $40-60$ day and 100-120 day Kelvin waves, respectively. North of the critical latitude, the Kelvin wave becomes coastally trapped.

[34] MJOs develop over the western tropical Indian Ocean and propagate slowly eastward across the IO [Madden and Julian, 1972; Wheeler and Hendon, 2004; Zhang, 2005]. During boreal summer, they move northward into the BoB and are associated with large sea surface temperature variations [Vecchi and Harrison, 2002; Roxy and Tanimoto, 2007]. Whether SSH signal exhibits northward propagation associated with northward-propagating MJOs is not clear. As shown in Figure 19, no $\mathrm{SSH}$ signal is observed propagating northward into the interior $\mathrm{BoB}$ in summer. The SSH in the interior BoB are mainly modulated by the westward-propagating Rossby waves which radiated from the eastern coast.

[35] Eddies are an important source of SSH ISV along their preferred pathways. We detect two preferred eddy pathways in the altimeter data: one along the western boundary and the other across the central Bay. Eddy activity contributes considerably to the strong SSH ISV in the western BoB. We carried out an energetics analysis to evaluate the instability of the mean flow and its contribution to $\mathrm{SSH}$ ISV. TEE features distinct seasonal variations. In summer, high TEE is located east of Sri Lanka, due to the instability of the SMC. In autumn, high TEE and positive $T 2+T 4$ are found along the western boundary of BoB. Significant correlation between TEE and $T 2$ indicates that baroclinic instability is the main mechanism for energy conversion. To the east of Sri Lanka, the high TEE in summer may be caused by barotropic instability of the SMC. The high TEE regions are collocated with high ISV in the western BoB, indicating the importance of barotropic/baroclinic instability for SSH ISV.

[36] The present work focuses on SSH ISV in the BoB and the mechanisms. The role of SSH ISV in intraseasonal airsea interactions and its impacts on sea surface temperature, the mixed layer, and barrier layer are interesting topics for future investigations.

[37] Acknowledgments. This work was supported by the National Basic Research Program of China (2010CB950303, 2012CB955600), the Natural Science Foundation of China (41176023, 41176024), U.S. NSF, NASA, and JAMSTEC. The work was initiated when X.H.C. was a visiting scholar at the International Pacific Research Center (IPRC). X.H.C. is also sponsored by the "Youth Innovation Promotion Association", CAS. The constructive remarks by two anonymous reviewers are greatly appreciated. The IPRC/SOEST Publication 945/8852.

\section{References}

Böning, C., and R. G. Budich (1992), Eddy dynamics in a primitive equation model: Sensitivity to horizontal resolution and friction, J. Phys. Oceanogr., 22, 361-381, doi:10.1175/1520-0485(1992)022<0361: EDIAPE > 2.0.CO;2.

Babu, M. T., Y. V. B. Sarma, V. S. N. Murty, and P. Vethamony (2003), On the circulation in the Bay of Bengal during northern spring inter-monsoon (March-April 1987), Deep-Sea Res. Part II, 50, 855-865, doi:10.1016/ S0967-0645(02)00609-4. 
Boyer, T. P., and S. Levitus (1997), Objective Analyses of Temperature and Salinity for the World Ocean on a $1 / 4^{\circ}$ Grid, NOAA Atlas NESDIS, vol. 11, NOAA, Silver Spring, Md.

Chang, C.-H., S.-P. Xie, N. Schneider, B. Qiu, J. Small, W. Zhuang, B. Taguchi, H. Sasaki, and X. Lin (2012), East Pacific ocean eddies and their relationship to subseasonal variability in Central American wind jets, J. Geophys. Res., 117, C10001, doi:10.1029/2011JC007315.

Chelton, D. B., R. A. DeSzoeke, M. G. Schlax, K. El Naggar, and N. Siwertz (1998), Geographical variability of the first baroclinic Rossby radius of deformation, J. Phys. Oceanogr., 28, 433-460.

Clarke, A. J., and C. Shi (1991), Critical frequencies at ocean boundaries, J. Geophys. Res., 96, 10,731-10,738.

Clarke, A. J., and X. Liu (1994), Interannual sea level in the northern and eastern Indian Ocean, J. Phys. Oceanogr., 24, 1224-1235.

Dibarboure, G., O. Lauret, F. Mertz, V. Rosmorduc, and C. Maheu (2008), SSALTO/DUACS User Handbook: (M)SLA and (M)ADT Near-Real Time and Delayed Time Products, Rep. CLS-DOS-NT-06.034, 39 pp., Aviso Altimetry, Ramonville St. Agne, France.

Eden, C., and C. Böning (2002), Sources of eddy kinetic energy in the Labrador Sea, J. Phys. Oceanogr. 32, 3346-3363, doi:10.1175/15200485(2002)032<3346:SOEKEI >2.0.CO;2.

Eigenheer, A., and D. Quadfasel (2000), Seasonal variability of the Bay of Bengal circulation inferred from TOPEX/Poseidon altimetry, J. Geophys. Res., 105(C2), 3243-3252, doi:10.1029/1999JC900291.

Emery, W. J., and R. E. Thomson (2001), Data Analysis Methods in Physical Oceanography, 2nd ed. revised, 654 pp. Elsevier Science, Amsterdam.

Ferrari, R., and C. Wunsch (2009), Ocean circulation kinetic energyreservoirs, sources and sinks, Ann. Rev. Fluid Mech., 41, 253-282, doi:10.1146/annurev.fluid.40.111406.102139.

Fu, L.-L. (2007), Intraseasonal variability of the equatorial Indian Ocean observed from sea surface height, wind, and temperature data, J. Phys. Oceanogr., 37(2), 188-202, doi:10.1175/JPO3006.1.

Girishkumar, M. S., M. Ravichandran, M. J. McPhaden, and R. R. Rao (2011), Intraseasonal variability in barrier layer thickness in the south central Bay of Bengal, J. Geophys. Res., 116, C03009, doi:10.1029/ 2010JC006657.

Goswami, B. N. (2005), South Asian summer monsoon, in Intraseasonal Variability of the Atmosphere-Ocean Climate System, edited by K. Lau and D. Waliser, 19-61, Praxis Publishing.

Han, W. (2005), Origins and dynamics of the 90-day and 30-60-day variations in the equatorial Indian Ocean, J. Phys. Oceanogr., 35, 708-728, doi:10.1175/JPO2725.1.

Han, W. Q., D. M. Lawrence, and P. J. Webster (2001), Dynamical response of equatorial Indian Ocean to intraseasonal winds: Zonal flow. Geophys. Res. Lett., 28, 4215-4218.

Han, W. Q., J. P. McCreary Jr., Y. Masumoto, J. Vialard, and B. Duncan (2011), Basin resonances in the equatorial Indian Ocean. J. Phys. Oceanogr., 41, 1252-1270, doi:10.1175/2011JPO4591.1.

Han, W., and P. J. Webster (2002), Forcing mechanisms of sea level interannual variability in the Bay of Bengal, J. Phys. Oceanogr., 32(1), 216-239, doi:10.1175/1520-0485(2002)032<0216:FMOSLI > 2.0.CO;2.

Horii, T., Y. Masumoto, I. Ueki, S. P. Kumar, and K. Mizuno (2011), Intraseasonal vertical velocity variation caused by the equatorial wave in the central equatorial Indian Ocean, J. Geophys. Res., 116, C09005, doi:10.1029/2011JC007081

Iskandar, I., T. Tozuka, H. Sasaki, Y. Masumoto, and T. Yamagata (2006), Intraseasonal variations of surface and subsurface currents off Java as simulated in a high-resolution ocean general circulation model, J. Geophys. Res., 111, C12015, doi:10.1029/2006JC003486.

Iskandar, I., W. Mardiansyah, Y. Masumoto, and T. Yamagata (2005), Intraseasonal Kelvin waves along the southern coast of Sumatra and Java, J. Geophys. Res., 110, C04013, doi:10.1029/2004JC002508.

Jensen, T. G. (2001), Arabian Sea and Bay of Bengal exchange of salt and tracers in an ocean model, Geophys. Res. Lett., 28(20), 3967-3970, doi:10.1029/2001GL013422.

Kalnay, E., et al. (1996), The NCEP/NCAR 40-year reanalysis project, Bull. Am. Meteorol. Soc., 77, 437-471, doi:10.1175/1520-0477077<0437: TNYRP $>2.0 . C O ; 2$.

Kumar, P. S., M. Nuncio, N. Ramaiah, S. Sardesai, J. Narvekar, F. Veronica, and T. P. Jane (2007), Eddy-mediated biological productivity in the Bay of Bengal during fall and spring intermonsoons, Deep Sea Res., Part I, 54, 1619-1640, doi:10.1016/j.dsr.2007.06.002.

Kumar, P. S., M. Nuncio, J. Narvekar, A. Kumar, S. Sardesai, S. N. de Souza, M. Gauns, N. Ramaiah, and M. Madhupratap (2004), Are eddies nature's trigger to enhance biological productivity in the Bay of Bengal?, Geophys. Res. Lett., 31, L07309, doi:10.1029/2003GL019274.

Kurien, P., M. Ikeda, and V. K. Valsala (2010), Mesoscale variability along the east coast of India in spring as revealed from satellite data and OGCM simulations, J. Oceanogr., 66, 273-289, doi:10.1007/ s10872-010-0024-X.
Lorenz, E. (1955), Available potential energy and the maintenance of the general circulation, Tellus, 7, 157-167.

Madden, R. A., and P. R. Julian (1972), Description of global-scale circulation cells in the tropics with a 40-50 day period, J. Atmos. Sci., 28, 3138-3158.

Masumoto Y. (2010), Sharing the results of a high-resolution ocean general circulation model under a multi-discipline framework?-A review of OFES activities, Ocean Dyn., 60(3), 633-652, doi:10.1007/s10236-010-0297-z.

Masumoto, Y., et al. (2004), A fifty-year eddy-resolving simulation of the world ocean-Preliminary outcomes of OFES (OGCM for the Earth Simulator), J. Earth Simulator, 1, 31-52.

McCreary, J. P., Jr., P. K. Kundu, and R. L. Molinari (1993), A numerical investigation of dynamics, thermodynamics and mixed-layer processes in the Indian Ocean, Prog. Oceanogr., 31, 181-244.

Miyama, T., J. P. McCreary Jr., T. G. Jensen, D. Sengupta, and R. Senan (2006), Dynamics of biweekly oscillations in the equatorial Indian Ocean, J. Phys. Oceanogr., 36, 827-846, doi:10.1175/JPO2897.1.

Moore, D. W., and J. P. McCreary Jr. (1990), Excitation of intermediatefrequency equatorial waves at a western ocean boundary: With application to observations from the Indian Ocean, J. Geophys. Res., 95(C4), 5219-5231, doi:10.1029/JC095iC04p05219.

Oliver, E. C. J., and K. R. Thompson (2010), Madden-Julian Oscillation and sea level: Local and remote forcing, J. Geophys. Res., 115, C01003, doi:10.1029/2009JC005337.

Pedlosky, J. (2003), Waves in the ocean and atmosphere, in Introduction to Wave Dynamics, 268 pp, Springer.

Perigaud, C., J. P. McCreary Jr., and K. Q. Zhang (2003), Impact of interannual rainfall anomalies on Indian Ocean salinity and temperature variability, J. Geophys. Res., 108(C10), 3319, doi:10.1029/ 2002JC001699.

Qiu, B., M. Mao, and Y. Kashino (1999), Intraseasonal variability in the Indo-Pacific throughflow and the regions surrounding the Indonesian Seas, J. Phys. Oceanogr., 29, 1599-1618.

Rao, A. S., S. K. Behera, Y. Masumoto, and T. Yamagata (2002), Interannual subsurface variability in the tropical Indian Ocean with a special emphasis on the Indian Ocean Dipole, Deep Sea Res., Part II, 49, 1549-1572, doi:10.1016/S0967-0645(01)00158-8.

Rao, R. R., M. S. Girish Kumar, M. Ravichandran, A. R. Rao, V. V. Gopalakrishna, and P. Thadathil (2010), Interannual variability of Kelvin wave propagation in the wave guides of the equatorial Indian Ocean, the coastal Bay of Bengal and the southeastern Arabian Sea during 1993-2006, Deep Sea Res., Part I, 57(1), 1-13, doi:10.1016/j. dsr.2009.10.008.

Reppin, J., F. Schott, and J. Fischer (1999), Equatorial currents and transports in the upper central Indian Ocean: Annual cycle and interannual variability, J. Geophys. Res., 104(C7), 15,495-15,514.

Rio, M. H., S. Guinehut, and G. Larnicol (2011), New CNES-CLS09 global mean dynamic topography computed from the combination of GRACE data, altimetry, and in situ measurements, J. Geophys. Res., 116, C07018, doi:10.1029/2010JC006505.

Roxy, M., and Y. Tanimoto (2007), Role of SST over the Indian Ocean in influencing the intraseasonal variability of the Indian summer monsoon, J. Meteorol. Soc. Jpn., 85, 349-358.

Sasaki, H., Y. Sasai, S. Kawahara, M. Furuichi, F. Araki, A. Ishida, Y. Yamanaka, Y. Masumoto, and H. Sakuma (2004), A series of eddy resolving ocean simulations in the world ocean-OFES (OGCM for the Earth Simulator) project, paper presented at OCEANS 2004 Mar. Technol. Soc., Inst. of Electr. and Electr. Eng., Kobe, Japan.

Sasaki, H., and M. Nonaka (2006), Far-reaching Hawaiian Lee Countercurrent driven by wind-stress curl induced by warm SST band along the current, Geophys. Res. Lett., 33, L13602, doi:10.1029/2006GL026540.

Schott, F., and J. P. McCreary (2001), The monsoon circulation of the Indian Ocean, Prog. Oceanogr., 51, 1-123.

Sengupta, D., R. Senan, V. S. N. Murty, and V. Fernando (2004), A biweekly mode in the equatorial Indian Ocean, J. Geophys. Res., 109, C10003, doi:10.1029/2004JC002329.

Shetye, S. R., A. D. Gouveia, S. S. C. Shenoi, D. Sundar, G. S. Michael, and G. Nampoothiri (1993), The western boundary current of the seasonal subtropical gyre in the Bay of Bengal, J. Geophys. Res., 98(C1), 945-954, doi:10.1029/92JC02070.

Somayajulu, Y. K., V. S. N. Murty, and Y. V. B. Sarma (2003), Seasonal and inter-annual variability of surface circulation in the Bay of Bengal from TOPEX/Poseidon altimetry, Deep Sea Res., Part II, 50, 867-880, doi:10.1016/S0967-0645(02)00610-0.

Sreenivas, P., C. Gnanaseelan, and K.V.S.R. Prasad (2012), Influence of El Niño and Indian Ocean Dipole on sea level variability in the Bay of Bengal, Global Planet. Change, 80-81, 215-225, doi:10.1016/ j.gloplacha.2011.11.001. 


\section{CHENG ET AL.: SEA SURFACE HEIGHT ISV IN THE BOB}

Vecchi, G. A., and D. E. Harrison (2002), Monsoon breaks and subseasonal sea surface temperature variability in the Bay of Bengal, J. Clim., 15, 1485-1493, doi:10.1175/1520-0442(2002)015<1485:MBASSS > 2.0.CO;2.

Vialard, J., S. S. C. Shenoi, J. P. McCreary, D. Shankar, F. Durand, V. Fernando, and S. R. Shetye (2009), Intraseasonal response of the northern Indian Ocean coastal waveguide to the Madden-Julian Oscillation, Geophys. Res. Lett., 36, L14606, doi:10.1029/2009GL038450.

Volkov, D. L., G. Larnicol, and J. Dorandeu (2007), Improving the quality of satellite altimetry data over continental shelves, J. Geophys. Res., 112, C06020, doi:10.1029/2006JC003765.

Wang, G., J. Su, and P. C. Chu (2003), Mesoscale eddies in the South China Sea observed with altimeter data, Geophys. Res. Lett., 30(21), 2121, doi:10.1029/2003GL018532.

Webber, B. G. M., D. P. Stevens, A. J. Matthews, and K. J. Heywood (2012), Dynamical ocean forcing of the Madden-Julian Oscillation at lead times of up to five months, J. Clim., 25, 2824-2842, doi:10.1175/ JCLI-D-11-00268.1.

Webber, B. G. M., A. J. Matthews, and K. J. Heywood (2010), A dynamical ocean feedback mechanism for the Madden-Julian Oscillation, Quart. J. Roy. Meteor. Soc., 136, 740-754, doi:10.1002/qj.604.
Wheeler, M. C., and H. H. Hendon (2004), An all-season real-time multivariate MJO index: Development of an index for monitoring and prediction, Mon. Weather Rev., 132(8), 1917-1932, doi:10.1175/15200493(2004)132<1917:AARMMI>2.0.CO;2.

Yu, L., J. J. O'Brien, and J. Yang (1991), On the remote forcing of the circulation in the Bay of Bengal, J. Geophys. Res., 96(C11), 20,449-20,454, doi:10.1029/91JC02424.

$\mathrm{Yu}, \mathrm{Z}$., and J. Potemra (2006), Generation mechanism for the intraseasonal variability in the Indo-Australian basin, J. Geophys. Res., 111, C01013, doi:10.1029/2005JC003023.

Zamudio, L., H. E. Hurlburt, E. J. Metzger, S. L. Morey, J. J. O’Brien, C. Tilburg, and J. Zavala-Hidalgo (2006), Interannual variability of Tehuantepec eddies, J. Geophys. Res., 111, C05001, doi:10.1029/ 2005JC003182.

Zhang, C. (2005), Madden-Julian Oscillation, Rev. Geophys., 43, RG2003, doi:10.1029/2004RG000158.

Zhuang, W., S.-P. Xie, D. Wang, B. Taguchi, H. Aiki, and H. Sasaki (2010), Intraseasonal variability in sea surface height over the South China Sea, J. Geophys. Res., 115, C04010, doi:10.1029/ 2009JC005647. 